\title{
An Analysis of How to Offer the Vocational Guidance by Internet in China
}

\author{
Xiaojiang Chen \\ Jiangsu Agri-animal Husbandry Vocational College \\ Taizhou City, Jiangsu Province, China \\ cq_cxj@126.com
}

\author{
Qixiang Sun* \\ Jiangsu Agri-animal Husbandry Vocational College \\ Taizhou City, Jiangsu Province, China \\ dwddwd98@126.com
}

\begin{abstract}
In order to make the vocational guidance of higher vocational colleges adjust to the new normal in the background of Internet, the paper using the method of investigation and literature research to analyze the strategies to strengthen the vocational guidance by Internet. The results showed that the main problems are lack of awareness of students' occupation guidance, lack of edification for students' occupation culture, occupation instructors are insufficient, lack of occupation guidance service consciousness. The author suggest using the Internet to help students renew their employment concept, optimize the information service management system, set up a university employment resource sharing platform, and encourage innovation and Entrepreneurship.
\end{abstract}

Keywords-Internet; Higher vocation; Vocational guidance; Career Guidance

\section{INTRODUCTION}

Mobile Internet is used widely in China, with a population of 688 million users until December, 2015 [1]. Phone is the main mobile terminal and has a large population of users in students. With the entrance of campuses, mobile Internet not only brings sweeping changes to students' life and studies but also gives a new chance for them to find a job [2]. From the view of vocational guidance, how to help unemployed graduates to make proper career plans and a suitable concept of employment and cultivate the innovative abilities of starting a business is an important study in the current situation [3].

\section{THE FEATURES OF INTERNET}

In 2015, Prime Minister Li pointed out in the report of government to advance the healthy development of ECommerce, industry and finance with the combination of Internet, Big Data and cloud computing. The core of Internet is "net", which has been permeating into the modern life gradually. The typical features of Internet as followed.

\section{A. Convenience}

Compared with traditional communications, Internet is more convenient, lower cost and energy for big date could make complex things to be easier through software.

\section{B. Open}

In the Internet, netizens build their own communication center through We Media, such as MicroBlogs, WeChat and blog to keep connection with outer world and get and share network resources without the limitation of time and space.

\section{Equality}

In virtual cyberspace, everyone is equal and has the same chance to express her or his will and perform as well as the equality of rights to upload or download resources and enjoy the right of offering opinions or commenting

\section{THE STATUS OF CURRENT WORK OF THE VOCATIONAL GUIDANCE}

Survey shows that $34.6 \%$ of Freshmen in 2015 of the students said in great need for occupation guidance, $58.7 \%$ of the students expressed the need for occupation guidance, the total demand for $93.9 \%$ of the number of students surveyed. In the "Career Guidance Expectations form", 25.1\% of the students hope to "advance into the vocational training system for learning and training", $21.1 \%$ of the students hope to "Interactive with enterprise and multiple forms of communication", $12.5 \%$ of the students hope to "career instructor's face to face consultation", $11.9 \%$ of the students hope to "experienced sharing of alumni", $10.1 \%$ of the students hope to participate in the "employment and occupation planning seminar, $9.8 \%$ of the students hope to obtain" self recommendation techniques", $9.4 \%$ of the students are eager to get the "occupation planning expert guidance"(Figure 1). This shows that the vast majority of the students demand the high quality of the occupation guidance, hope according to their own interests, hobbies and expertise, through the "tailored", to measure the gap between ourselves and the right to set their own goals in life, and then choose their own development of occupation.

Because of abreast of the market and industry demand, the great attention of employment, the higher vocational colleges make a step to set up special employment institution, develop relevant courses, hold the activities about career plans, invite companies to make a careers talks and organize job fairs, etc. Therefore, to some degree, the employment rate of vocational school students is higher than undergraduate students [4]. 
However, it is lack of some Internet thinking, which is presented in the following points.

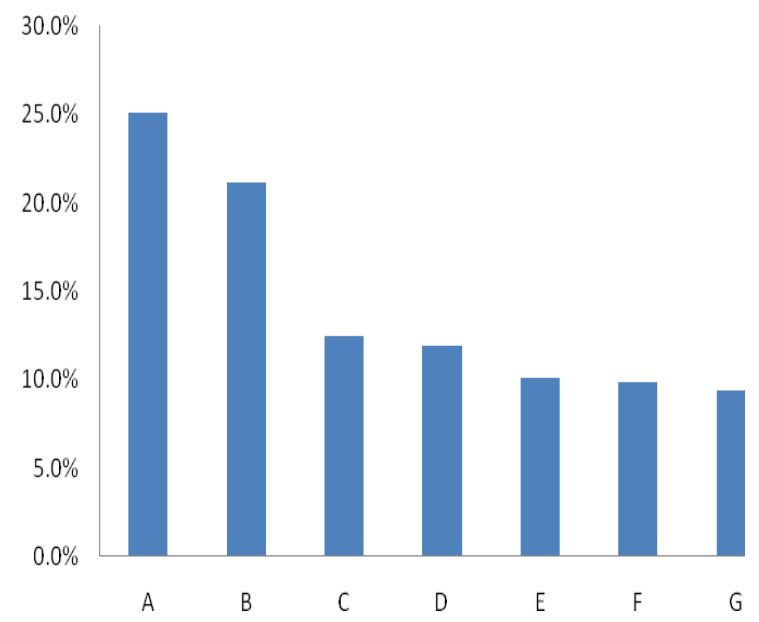

Fig. 1 Career Guidance Expectations of 2015 Freshmen

A. Advance into the vocational training system for learning and training

B. Interactive with enterprise and multiple forms of communication

C. Career instructor's face to face consultation

D. Experienced sharing of alumni

E. Employment and occupation planning seminar

F. Self recommendation techniques

G. Occupation planning expert guidance

\section{A. The insufficient awareness of the aim of vocational} guidance

Now, the work of vocational guidance belongs to transactional work, which highlights the intensive vocation guidance and careers talks, the publicity education, the collection and transmission of job information as well as the job fairs, etc. Although the higher vocational colleges have realized the importance of vocational guidance, the actual practice is a surface work. It is necessary to learn that the aim of vocational guidance is not only to help students to find a satisfying job but also to cultivate them to be a talent to been needed in every walk of life..

\section{B. The insufficient edifying influence of vocational culture on students}

Vocational students are lack of self-control. Higher vocational colleges should not only attach importance to the education of professional skills but also exert an edifying culture influence to develop students' spirit of hard-working. It is better for students to pursue value and do suitable careers plan under a well cultural campus environment.

\section{The insufficient of the staff of vocational guidance}

According to the survey, the work of vocational guidance is practised by recruitment and employment office, the rate of teachers and students is 1:1000 while the rate of developed countries is 1:200 [5], therefore, the amount of the teachers are not enough. The macroteaching is lack of personalized guidance one by one. China is short of professional teachers for the work of vocational guidance is usually implemented by non-professional teachers, such as instructors, administrators. As a result, it is difficult to guarantee the equality of vocational guidance.

\section{The insufficient awareness of vocational guidance service}

The ways of vocational guidance service of traditional colleges are single and boring like lectures and job fairs, which couldn't attract students' attention well [6]. The students' connection with schools may be interrupted for the change of phone number. Because the school is lack of management awareness of graduates, they couldn't provide the employment information for the unemployed students. Besides, they couldn't send the information of the part students to companies timely. In the process of the vocational guidance, lack of concern for the individual needs of students is a common problem.

\section{THE ANALYSIS OF THE STRATEGIES TO STRENGTHEN THE VOCATIONAL GUIDANCE BY INTERNET}

\section{A. Helping students to make proper career plans and a suitable concept of employment}

Through the vocational students have not so much pressure of employment, it is still necessary and important for them to do well career plans and career concept, improve their comprehensive quality and face the pressure. According to the different characteristics of students in different times, the schools should adjust and improve the talent-developing plans and curriculum standards and make the vocational guidance throughout the talent cultivation. At present, the main students are after 90s. Traditional teaching model can't meet the requirements of education and the employment instruction is not systematic. Therefore, the higher vocational colleges could utilize some new ways to develop the work of vocational guidance, such as Netease Classroom, MOOC [7], Cloud classroom and Microlecture. A new trend attracts students more easily, which can help students to establish new concepts on vocation and employment. The related personnel can make a full use of Internet through Office Automation System, WeChat, QQ and MircoBlog to communicate with students [8] solve some problems and help build a well - fixed vocational concept. Also, the schools should encourage students to overcome the negative thoughts and change the main employment directions like state-owned businesses, public institution into diversified industries and the emerging industries in Internet.

\section{B. The optimizations of Information Security Management System by Internet technology}

As there are kinds of reasons why so many high school graduates are unemployed, it is a necessary to collect the students' data files which include majors, hobbies and career plans to analyze the demand of students and share the information with companies based on the big date like WeChat Official Account. As a result, the efficiency of vocational guidance is improved by the combination of schools, employer and graduates. Registering a vocational 
WeChat Official Account Through the full use of the convenient and widespread WeChat is a way to express information timely and do a match of students and jobs. The big date is a good way to analyze the requirements of students and companies and present the advantages and hobbies of students and solve the problems of unemployment.

\section{Building a sharing platform about employment information by Internet}

Make full use of the Internet to integrate employment resources and optimize the guidance services.

1) To build a cooperation platform of resources between schools and industries. The schools can connect their own interface with industries, which is convenient for students to look for suitable employment information and find a satisfying job. Besides, the online interview costs a lower time and money.

2) To build a resources platform between alumni. Collecting the information of outstanding alumni, building a bulletin board and introducing their life experience, inspirational stories and sharing their successful experience through a micro-video and courseware is also a way to help students to build a proper employment concept and know the kinds of industries previously. And then the students can make a better preparation after the find their deficiency.

3) To build a resources platform between colleges. To share the employment information is a way to reduce workload on recruitment and to enlarge the employment information. And then, it contributes students to find more chances for a job.

\section{TO ENCOURAGE STUDENT TO INNOVATE AN EMERGING INDUSTRY}

In the process of vocational guidance, it is necessary for the students and teachers to work together to develop innovation consciousness, incubate entrepreneurship programs and improve the independently entrepreneurial ability

- Strengthening the publicity guide. Government issues some documents of university entrepreneurship; the schools cultivate the hobby of entrepreneurship and provide the useful information for students through QQ, WeChat and so on.

- Building incubation bases. The schools could use training bases inside and outside school to build incubation bases. The incubation bases can use the model of "Front Shop, Back Factory". Under the model of Front Shop, Back Factory, the vocational guidance is practised by professional teachers and experienced part-time teachers to make a complete and management system and build a group for examine, attendance and evaluation. Besides, the schools can use the media to publicize the typical entrepreneurship cases, pass positive energy and encourage more students to join the entrepreneurship groups.

- Strengthen the training of innovation and Entrepreneurship. The encouragement of students to apply the entrepreneurship project in Jiangsu is a way to improve the entrepreneurial ability. Encouraging students to join kinds of entrepreneurial contests, such as Youth Science Creation Competition, Internet entrepreneurship competition and so on in Jiangsu is contributed to students to develop the innovational awareness. There are so many way for schools to improve students' innovation consciousness and entrepreneurial ability. For example, revising the talent training scheme, setting entrepreneurial course like 'Know About Business'(KAB), 'START YOUR BUSINESS'(SYB), improving the second classroom, building incentive mechanism of instructors and reward mechanism of students

\section{VI. . CONCLUSION}

The higher vocational colleges are lack of some Internet thinking, which is presented in the following points. The insufficient awareness of the aim of vocational guidance; the insufficient edifying influence of vocational culture on students; the insufficient of the staff of vocational guidance; the insufficient awareness of vocational guidance service

The authors suggest helping students to make proper career plans and a suitable concept of employment; the optimizations of Information Security Management System by Internet technology; Building a sharing platform about employment information by Internet

- To build a cooperation platform of resources between schools and industries.

- To build a resources platform between alumni.

- To build a resources platform between colleges

At last, the authors suggest encouraging student to innovate an emerging industry.

- Strengthening the publicity guide.

- Building incubation bases.

- Strengthen the training of innovation and Entrepreneurship.

\section{ACKNOWLEDGMENT}

The authors are thankful to Jiangsu University Philosophy and Social Science Research Fund Project support (Grant NO: 2015SJB863). Research on Teaching Reform of Higher Education in Jiangsu Province for financial support (Grant NO: 2015JSJG592).

\section{REFERENCES}

[1] $\mathrm{Li} \mathrm{X}, \mathrm{He} \mathrm{X}$. Acceptance analysis of mobile internet in China [J]. International Journal of Mobile Communications, 2015, 13(4):398.

[2] Gong Y H, Li B, Li D. The Price Strategy and Mobile Internet Supply Chain Coordination Mechanism in China[C]// International Conference on E-Business and E-Government. IEEE, 2010:2170-2173.

[3] Savickas M L, Esbroeck R V, Herr E L. The Internationalization of Educational and Vocational Guidance [J]. The Career Development Quarterly, 2005, 54(1):77-85.

[4] Hongmei L I. A Study on the Psychological Guidance Tactics of Students in Higher Vocational Colleges in the Internet Age [J]. Shipbuilding Vocational Education, 2016. 
[5] Valach L, Young R A. Interdisciplinarity in vocational guidance: an action theory perspective [J]. International Journal for Educational and Vocational Guidance, 2009, 9(2):85-99.

[6] Esbroeck R V, Herr E L, Savickas M L. Introduction to the Special Issue: Global Perspectives on Vocational Guidance [J]. The Career Development Quarterly, 2005, 5(1):85-90.
[7] Yang Y. The Application of Career-Guiding MOOC Course in Undergraduate Colleges[C]// Eighth International Conference on Measuring Technology and Mechatronics Automation. IEEE Computer Society, 2016:681-683.

[8] Sampson J P. Quality and Ethics in Internet-Based Guidance [J]. International Journal for Educational and Vocational Guidance, 2002, 2(3):157-171 